\title{
Investigation of AWG demultiplexer based SOI for CWDM application
}

\author{
Nurjuliana Juhari ${ }^{1}$, P Susthitha Menon $^{2}$, Sahbudin Shaari ${ }^{2}$, Abang Annuar Ehsan ${ }^{2}$ \\ ${ }^{1}$ School of Microelectronic Engineering, Universiti Malaysia Perlis (UniMAP), 02600 Arau, Perlis and ${ }^{2}$ Institute of Microengineering \\ ${ }^{2}$ Nanoelectronics (IMEN), Universiti Kebangsaan Malaysia (UKM), 43600 UKM Bangi, Selangor, Malaysia
}

\begin{abstract}
Arrayed Waveguide Grating (AWG) demultiplexer for conventional and tapered structure were simulated using beam propagation method (BPM) with channel spacing of $20 \mathrm{~nm}$. The AWG demultiplexer was design using high refractive index ( $\mathrm{n}$ 3.47) material namely silicon-on-insulator (SOI) with rib waveguide structure. The characteristics of insertion loss, adjacent crosstalk and output spectrum response at central wavelength of $1.55 \mu \mathrm{m}$ for both designs were compared and analyzed. The conventional AWG produced a minimum insertion loss of $6.64 \mathrm{~dB}$ whereas the tapered AWG design reduced the insertion loss by $2.66 \mathrm{~dB}$. The lowest adjacent crosstalk value of $-16.96 \mathrm{~dB}$ was obtained in the conventional AWG design and this was much smaller compared to the tapered AWG design where the lowest crosstalk value is $-17.23 \mathrm{~dB}$. Hence, a tapered AWG design significantly reduces the insertion loss but has a slightly higher adjacent crosstalk compared to the conventional AWG design. On the other hand, the output spectrum responses that are obtained from both designs were close to the Coarse Wavelength Division Multiplexing (CWDM) wavelength grid.
\end{abstract}

\section{Introduction}

Planar lightwave circuits (PLC) are waveguide devices that are fabricated on flat substrates, commonly on silicon or glass. PLCs are also widely utilized in wavelength-division multiplexing (WDM), time-divison multiplexing (TDM) systems and fiber-to-the-home (FTTH) access networks [1]. WDM systems have some key components that have the function to multiplexer/demultiplexer (mux/demux) signal that can increase transmission capacity on a single optical fiber. These components are such as the Arrayed Waveguide Grating (AWG), Echelle gratings, ring resonators and lattice form filters. Actually, the research on mux/demux that focused on grating based and phased array (PHASAR) based devices were developed since 1990 [2]. Silica was the first material that was widely used in developing AWGs. In the late 1990's, a 64-channel 50 $\mathrm{GHz} \mathrm{InP}$ based AWG was developed [3] and this was followed by other materials such as polymer, $\mathrm{Al}_{2} \mathrm{O}_{3}$, $\mathrm{SiGe}, \mathrm{LiNbO}_{3}$ and silicon-on-insulator (SOI) materials. Since silicon is widely used in the microelectronics industry, integration between silicon photonics and electronic devices became more interesting. Based on sophisticated semiconductor technology, [4] it is predicted that silicon photonics would provide inexpensive integrated electronics-photonics platform. Therefore, the Array Waveguide Grating (AWG) developed on a SOI-based rib waveguide have great potential especially for WDM systems.

In this work, we designed a novel SOI-based AWG mux/demux with channel spacing catering for Coarse
Wavelength Division Multiplexing (CWDM) networks. Two different designs of the AWG device were developed; one with a conventional waveguide and the other with a tapered design. The insertion loss and adjacent crosstalk values of both designs were analyzed and compared with. The output transmission peak from this AWG device was then verified using standard International Transmission Unit (ITU) wavelength grid for $\mathrm{WDM} / \mathrm{CWDM}$ system.

\section{Fundamental theory of arrayed waveguide gratings (AWG)}

Fig. 1 (a) shows the schematic of an rib optical waveguide (cross-section) while Fig. 1 (b) shows the effective refractive index, $n_{\text {eff }}$ value of the rib waveguide at transverse mode, TE00 (single mode). The measurements were executed using RSOFT Fullwave software where the mathematical equations are based on finite difference method which gives $n_{\text {eff }}$ of 3.31715 . Layout of the AWG device is depicted in Fig. 2 and the circle signage show the tapered design located at the phase array and at the input/output region respectively. In an AWG, the fundamental mode is the correct operation that allows light to propagate through a waveguide with less dispersion. The design of the SOIbased rib waveguide structure with fundamental mode condition can be designed where the geometry of the waveguide is determined using Eq. (1) and (2) [6]. Silicon waveguide which is used as the core have a refractive index, $\mathrm{n} \sim 3.5$ and is surrounded with $\mathrm{SiO}_{2}$ as a 
cladding with $\mathrm{n} \sim 1.5$ which gives a step index value of $\Delta \mathrm{n} \sim 2$. In this design, the value of core width $\mathrm{W}$, core height $\mathrm{H}$, and etch depth $\mathrm{h}$, are $\mathrm{W}=1 \mu \mathrm{m}, \mathrm{H}=0.6 \mu \mathrm{m}$ and $\mathrm{h}=0.1 \mu \mathrm{m}$ respectively.

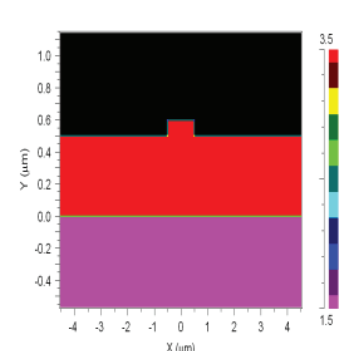

(a)

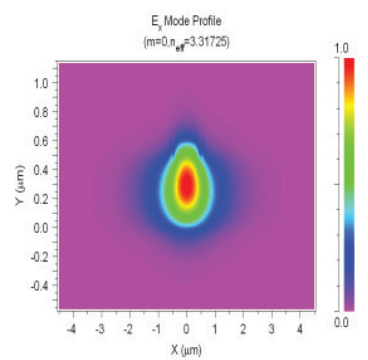

(b)
Fig. 1. (a) Cross section (b) Single mode pattern of $1 \mu \mathrm{m}$ core width of SOI-based rib waveguide

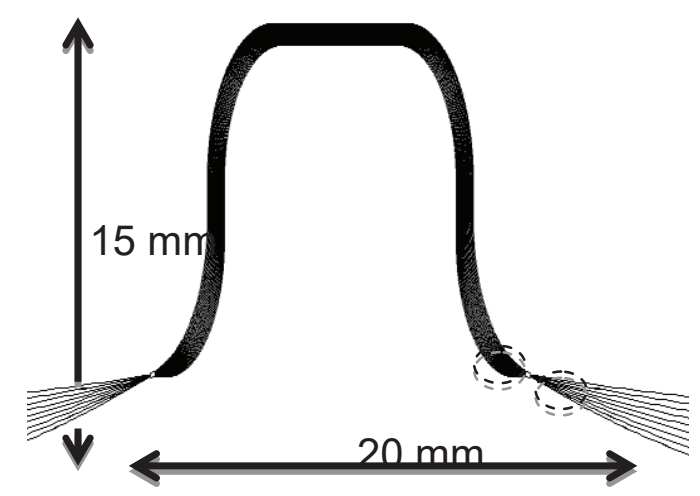

Fig. 2. Schematic layout of conventional 9-channel AWG and circle sign show the tapered design at phase array tapered designed at $\mathrm{I} / \mathrm{O}$ port region.

$$
\begin{gathered}
\frac{W}{H}=\alpha+\frac{\frac{h}{H}}{\sqrt{1-\left(\frac{h}{H}\right)^{2}}} \\
\frac{h}{H} \geq 0.5
\end{gathered}
$$

Basically, this AWG consist of 9 x 9 input and output waveguides, two free propagation regions (FPR) at length of $263.0688 \mu \mathrm{m}$ and 34 arrayed waveguides produced. Some important parameters are the input/output waveguide separation, D, arrayed waveguide separation, $d$, and the radius of curvature, $f$, at both FPRs. AWG works based on the interferometer principle. Light which carries different wavelength in one optical fiber propagating at the input waveguide is then diffracted at different diffraction order in the FPR. This light is then coupled into the arrayed waveguide. The arrayed waveguide is constructed based on Eq. 3 at central wavelength $\lambda_{c}, 1.55 \mu \mathrm{m}$ where $\Delta \mathrm{L}$ is the difference in the optical path length, $m$ is the order of the phased array, and $\mathrm{N}_{\mathrm{g}}$ is the modal effective index of the waveguide.

$$
\Delta \mathrm{L}=m \frac{\lambda_{c}}{N_{g}}
$$

The phase difference depends on the input wavelength. It can be determined when the light beam is channeledback into the output star coupler. The constructive interference in the second slab is then propagated through the output channel that brings about different wavelengths. To determine the channel spacing obtained at $20 \mathrm{~nm}$, Eq. 4 is used

$\Delta \lambda=\frac{n_{s} d D \lambda_{0}}{N_{c} f \Delta L}$

where $n_{s}$ is effective index at the FPR region, $d$ is arrayed waveguide separation, $\mathrm{D}$ is waveguide separation, $\lambda_{0}$ is the channel spacing, $\mathrm{N}_{\mathrm{c}}$ is the group index, $\mathrm{f}$ is the curvature radius and $\Delta \mathrm{L}$ is path length difference. A variety of loss mechanisms occur in AWGs but generally they are mainly contributed by the loss coming from the junction between the free propagation region and the waveguide array [7].

\section{Methodology}

The design and simulation was conducted using PHASAR software where the calculation is based on the beam propagation method (BPM) algorithm. BPM simulation gives accurate data such as loss and radiation in the arrayed waveguide, coupling of waveguide and phase error. Numerical method based on (effective index method) EIM is a popular technique in analyzing integrated optical devices meanwhile (S-matrix method) SMM used to analyze the phased array when the decoupling process occurs. The material used is SOI which have an effective index between core/cladding at $1550 \mathrm{~nm}$ of $3.31725 / 1.5$. The port separation of the input/output adjacent channels is designed to be $250 \mu \mathrm{m}$ to enable pigtailing to fiber ribbons [8]. The tapered design for width waveguide separation and length at input/output port is set at $5 \mu \mathrm{m}$ and $700 \mu \mathrm{m}$ respectively. All the result of the design parameters are tabulated in Table 1. The difference in the parameters between the conventional and the tapered AWG is only the size of waveguide width and the length of the taper while other parameters remain the same. The simulation results presents the value of adjacent crosstalk, channel spacing, bandwith at $-3 \mathrm{~dB}$ level and insertion loss.

Table 1. Design parameters of $1 \mu \mathrm{m}$ core width of conventional and tapered AWG device 


\begin{tabular}{|l|c|c|}
\hline & AWG Value & Value \\
\hline $\begin{array}{l}\text { I/O and array } \\
\text { waveguide } \\
\text { effective index }\end{array}$ & 3.2858 & 3.2858 \\
\hline $\begin{array}{l}\text { Free Propagation } \\
\text { Region (FPR) }\end{array}$ & $263.0688 \mu \mathrm{m}$ & $263.0688 \mu \mathrm{m}$ \\
\hline Number of Arrays & 34 & 34 \\
\hline $\begin{array}{l}\text { Modal index (I/O } \\
\& \text { array } \\
\text { waveguide) }\end{array}$ & 3.2559 & 3.2559 \\
\hline $\begin{array}{l}\text { Free Spectral } \\
\text { Range (FSR) }\end{array}$ & $32235.484 \mathrm{GHz}$ & $32235.484 \mathrm{GHz}$ \\
\hline $\begin{array}{l}\text { Optical path } \\
\text { length, } \Delta \mathrm{L}\end{array}$ & $2.83 \mu \mathrm{m}$ & $2.83 \mu \mathrm{m}$ \\
\hline Phasar order, m & 6 & 6 \\
\hline $\begin{array}{l}\text { Channel spacing, } \\
\Delta \lambda\end{array}$ & $20 \mathrm{~nm}$ & $20 \mathrm{~nm}$ \\
\hline $\begin{array}{l}\text { Central } \\
\text { wavelength, } \lambda_{0}\end{array}$ & $1.55 \mu \mathrm{m}$ & $1.55 \mu \mathrm{m}$ \\
\hline $\begin{array}{l}\text { Taper width and } \\
\text { length (I/O) }\end{array}$ & - & $2.3 \mu \mathrm{m} / 75.74$ \\
\hline $\begin{array}{l}\text { Taper width and } \\
\text { length (I/O) }\end{array}$ & - & $2.3 \mu \mathrm{m} / 75.74 \mu \mathrm{m}$ \\
\hline
\end{tabular}

However, the insertion loss does not reduce too much, therefore the tapered design is added at input/output star coupler. The angle tapers, $\alpha$ at width $2.5 \mu \mathrm{m}$ tapering waveguide produced the length, $\mathrm{L}_{\text {taper }}$ with the value of $75.74 \mu \mathrm{m}$. Table 2 and Table 3 shows the output parameter with $-3 \mathrm{~dB}$ bandwith for conventional and tapered design of 9 channel AWG device. Channel spacings of $20 \mathrm{~nm}$ are successfully produced where these designs are applicable for CWDM networks. However, for the conventional design, the channel spacing between channel 4 and 5 is $21.7 \mathrm{~nm}$. The same scenario also occurs at the tapered AWG design when the $21.7 \mathrm{~nm}$ spacing is produced at between channel 7 and channel 8 . The highest value of adjacent crosstalk is obtained at channel 5 for the tapered AWG which is much higher compared to the conventional AWG which gives the value of $-22.087654 \mathrm{~dB}$ and $-20.144659 \mathrm{~dB}$ respectively.

The same phenomena occurs at the lowest adjacent crosstalk where the minimum crosstalk for the conventional AWG is still less compared to the tapered AWG. Therefore the tapered and conventional AWG design has not much effect to the adjacent crosstalk. In comparison, these adjacent crosstalk values for both designs still presents a good performance when compared to previous designs [11] where the suggested crosstalk was indicated in the range of $\sim 35-37 \mathrm{~dB}$. In comparison, a fabricated $\mathrm{Si}$ nanowire-based AWG waveguide produced a general crosstalk with value of -8 $\mathrm{dB}$ [12] which shows that the developed designs have better crosstalk. The idea of the tapered design is to reduce the insertion loss especially at the phase arrayed waveguide. From the results in Table 3, it is found that the minimum insertion loss for a tapered design is about $50 \%$ lower as compared to the conventional design. This loss is due to the imperfect light capture loss [13] and diffraction loss [14] at the star coupler and array interface.

Fig. 3 (a) and (b) show the spectral response output of a 9-channel conventional AWG device where the simulations was set from $1440 \mathrm{~nm}$ until $1635 \mathrm{~nm}$ at 121 iteration steps. The wavelength for the nine output of the tapered design with $\lambda_{1}, \lambda_{2}, \lambda_{3}, \lambda_{4}, \lambda_{5} \lambda_{6}, \lambda_{7}, \lambda_{8}$, and $\lambda_{9}$ are located at $1454 \mathrm{~nm}, 1474 \mathrm{~nm}, 1494 \mathrm{~nm}, 1514 \mathrm{~nm}$, $1535.667 \mathrm{~nm}, 1555.667 \mathrm{~nm}, 1575.667 \mathrm{~nm}, 1595.667 \mathrm{~nm}$ and $1615.667 \mathrm{~nm}$ while for the conventional design $\lambda_{1}$, $\lambda_{2}, \lambda_{3}, \lambda_{4}, \lambda_{5} \lambda_{6}, \lambda_{7}, \lambda_{8}$, and $\lambda_{9}$ are located at $1454 \mathrm{~nm}$, $1474 \mathrm{~nm}, 1494 \mathrm{~nm}, 1514 \mathrm{~nm}, 1534 \mathrm{~nm}, 1554 \mathrm{~nm}$, $1575.667 \mathrm{~nm}, \quad 1595.667 \mathrm{~nm}$ and $1615.667 \mathrm{~nm}$ respectively. The value for each peak of the output response is based on the channel spacing as tabulated in Table 2 and Table 3. The results of peak wavelength for both designs are found to be slightly different. The reason is due to the channel spacing between some of the channels where the spacing is not exactly $20 \mathrm{~nm}$. However, if compared with ITU Grid [15] the wavelengths are still within the CWDM network [16]. 
Table 2. Output parameter calculated with $-3 \mathrm{~dB}$ bandwidth for 9 channel tapered AWG.

\begin{tabular}{|c|c|c|c|c|c|}
\hline Channel & Peak (dB) & $\begin{array}{c}\text { Crosstalk } \\
\mathbf{( d B )}\end{array}$ & $\begin{array}{c}\text { Spacing } \\
\mathbf{( n m )}\end{array}$ & $\begin{array}{c}\text { Peak Wavelength from } \\
\text { simulation (nm) }\end{array}$ & $\begin{array}{c}\text { Peak Wavelength: } \\
\text { G.694.2 } \\
\text { CWDM Wavelength } \\
\text { Grid (nm) }\end{array}$ \\
\hline 1 & -4.17 & -17.23 & 0.020 & $1454.000 \pm 5$ & 1451 \\
\hline 2 & -3.35 & -18.39 & 0.020 & $1474.000 \pm 5$ & 1471 \\
\hline 3 & -3.03 & -20.08 & 0.020 & $1494.000 \pm 5$ & 1491 \\
\hline 4 & -2.78 & -20.98 & 0.022 & $1514.000 \pm 5$ & 1511 \\
\hline 5 & -2.66 & -22.09 & 0.020 & $1535.667 \pm 5$ & 1531 \\
\hline 6 & -2.77 & -21.69 & 0.020 & $1555.667 \pm 5$ & 1551 \\
\hline 7 & -3.14 & -19.98 & 0.020 & $1575.667 \pm 5$ & 1571 \\
\hline 8 & -3.88 & -19.29 & 0.020 & $1595.667 \pm 5$ & 1591 \\
\hline 9 & -4.86 & -17.44 & - & $1615.667 \pm 5$ & 1611 \\
\hline
\end{tabular}

Table 3. Output parameter calculated with $-3 \mathrm{~dB}$ bandwidth for 9 channel conventional AWG

\begin{tabular}{|c|c|c|c|c|c|}
\hline Channel & $\begin{array}{c}\text { Peak } \\
(\mathbf{d B})\end{array}$ & $\begin{array}{c}\text { Crosstalk } \\
\mathbf{( d B )}\end{array}$ & $\begin{array}{c}\text { Spacing } \\
(\mathbf{n m})\end{array}$ & $\begin{array}{c}\text { Peak Wavelength from } \\
\text { simulation (nm) }\end{array}$ & $\begin{array}{c}\text { Peak Wavelength: } \\
\text { G.694.2 CWDM } \\
\text { Wavelength Grid } \\
\text { (nm) }\end{array}$ \\
\hline 1 & -7.62 & -16.96 & 0.020 & $1454.000 \pm 5$ & 1451 \\
\hline 2 & -7.06 & -17.71 & 0.020 & $1474.000 \pm 5$ & 1471 \\
\hline 3 & -6.80 & -18.85 & 0.020 & $1494.000 \pm 5$ & 1491 \\
\hline 4 & -6.72 & -19.69 & 0.020 & $1514.000 \pm 5$ & 1511 \\
\hline 5 & -6.64 & -20.14 & 0.020 & $1534.000 \pm 5$ & 1531 \\
\hline 6 & -6.94 & -19.27 & 0.020 & $1554.000 \pm 5$ & 1551 \\
\hline 7 & -7.26 & -19.34 & 0.022 & $1575.667 \pm 5$ & 1571 \\
\hline 8 & -8.02 & -18.54 & 0.020 & $1595.667 \pm 5$ & 1591 \\
\hline 9 & -8.905 & -17.99 & - & $1615.667 \pm 5$ & 1611 \\
\hline
\end{tabular}

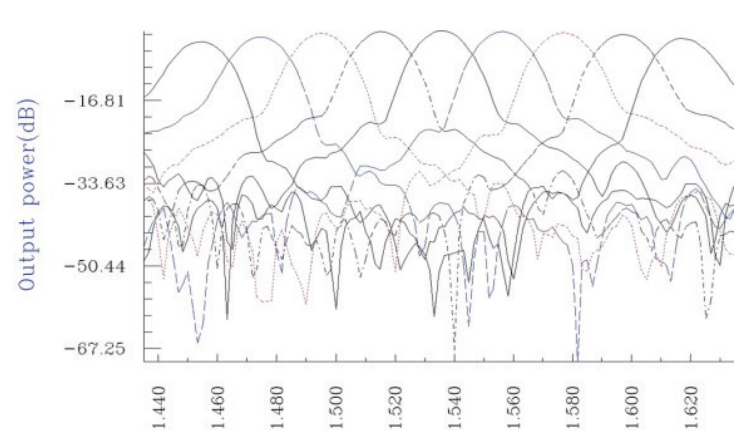

(a)

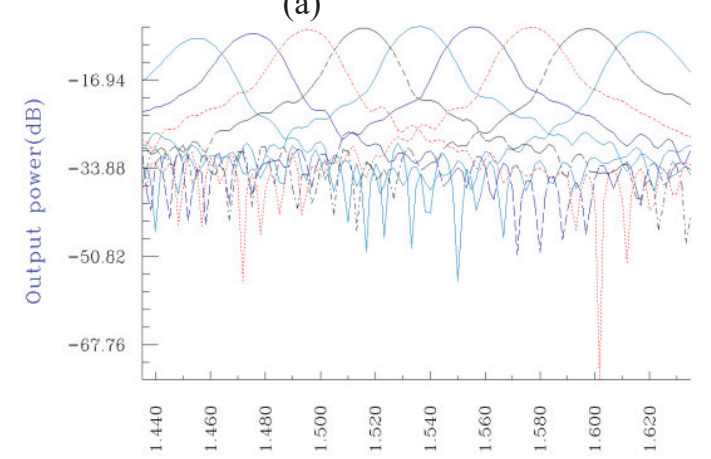

(b)

Fig. 3 : Output spectral response of 9 channel SOI-based CWDM AWG for (a) tapered AWG and (b) conventional AWG

\section{Conclusions}

Conventional and tapered 9 channels AWG-based rib waveguide structure SOI have been successfully designed to obtain a standard wavelength transmission in the optical windows of E, S, C and L for CWDM network. The conventional AWG produced a minimum insertion loss of $6.64 \mathrm{~dB}$ whereas the tapered AWG design reduced the insertion loss to $2.66 \mathrm{~dB}$. The lowest adjacent crosstalk value of $-16.96 \mathrm{~dB}$ was obtained in the conventional AWG design and this was much smaller compared to the tapered AWG design where the lowest crosstalk value is $-17.23 \mathrm{~dB}$. The output spectral response for 9-channel AWG for both designs satisfy the ITU grid of a CWDM network. In summary, a tapered AWG design significantly reduces insertion loss and has an equivalent adjacent crosstalk as compared to a conventional AWG.

The author would like to thank the Malaysian Ministry of Education and Universiti Kebangsaan Malaysia (UKM) for sponsoring this work under research grant FRGS/2/2013/SG02/UKM/02/4. The payment for this paper is supported by FRGS grant (9003-00405). 


\section{References}

1. K. Okamoto, Laser Photonics Rev. 1, 14-23, (2012).

2. M.K Smit, C.V. Dam, IEEE J. Sel. Topics Quantum Electron., 2, 236-250, (1996).

3. P. Cheben, Optical Waveguide From Theory to Applied Technologies CRC Press Taylor \& Francis Group, U.S, pp.173-230, (2007).

4. K.Yamada, Silicon Photonics II, SpringerVerlag, Berlin Heidelberg, pp.129 -187, (2011).

5. B. Chomycz, Planning Fiber Optics Networks, New York: McGraw Hills Company, (2009).

6. O. Powell, Single-mode Condition for Silicon Rib Waveguides, J. Lightw. Technol., 10, 1851- 1855, (2002).

7. X.J.M. Leijtens, B.Kuhlow, M.K. Smit, Filters in Fibre Optics, Springer, Berlin Germany, pp. 125-187, (2006).

8. H.C.Woei, N.A.Rahman, S. Shaari, ICSE2004, 473-476, (2004).

9. Q. Fang, F. Li, Y. Liu, Opt. Commun 2, 155158, (2006).

10. T. Fukazawa, F. Ohno, T. Baba, Jpn. J. Appl. Phys., 5B, 673-675, (2004).

11. I P Kaminow, C.R. Doerr, C. Dragone, T. Koch, U. Koren, IEEE J. Sel. Areas Commun., 14, 780-789, (1996).

12. Z. Lei, A. Jumming, Z. Jiashun, S. Shijiao, W. Yuanda, H. Xiongwei, J. Semicond., 32, 1-4, (2011).

13. K. Okamoto, Fundamental of Optical Waveguide, Elsevier, USA, (2005).

14. S.L. Tsao and Y.H. Lin, Proc. SPIE, (2004),.

15. H.J. Thiele, M. Nebeling, Coarse Wavelength Division Multiplexing Technologies and Application. Taylor \& Francis Group, USA, (2007).

16. N. Juhari, P.S. Menon, A.A. Ehsan, 4th Int. Conf. Photonics, 230 - 233, (2013). 